\title{
Long-Term Survival of a Patient
} with Giant Cell Glioblastoma: \section{Case Report and Review of the Literature}

\author{
E. Naydenov $\quad$ V. Bussarsky ${ }^{\mathrm{a}} \quad$ S. Nachev ${ }^{\mathrm{b}} \quad$ S. Hadjidekova ${ }^{\mathrm{c}}$ \\ D. Toncheva ${ }^{c}$ \\ ${ }^{a}$ Department of Neurosurgery, University Hospital St. Ivan Rilski, and Departments \\ of bPathology and 'Medical Genetics, Medical University, Sofia, Bulgaria
}

\section{Key Words}

Giant cell glioblastoma $\cdot$ Long-term survival $\cdot$ Microarray analysis

\begin{abstract}
Glioblastoma multiforme (GBM) is the most common glial tumor of the central nervous system. Overall survival is less than a year in most of the cases in spite of multimodal treatment approaches. A 45-year-old female with histologically confirmed giant cell GBM was treated at our institution. Subtotal excision of the lesion situated in the right precentral area was performed during the initial stay in August 2005. The patient improved after the procedure with no hypertension and additional neurological deficit. Radiotherapy plus concomitant and adjuvant temozolomide was performed. The patient was symptom-free for 35 months after initial surgery. From July 2008 the patient developed partial motor seizures in the left side of the body and progressive hemiparesis. Local tumor progression was demonstrated on the neuroimaging studies. In December 2008, a second operative intervention was performed with subtotal excision of the tumor. Forty-five months after the initial diagnosis the patient is still alive with moderate neurological deficit. Microarray analysis of the tumor found the following numeric chromosomal aberrations: monosomy $8,10,13,22$, and trisomy 21 , as well as amplifications in $4 q 34.1,4 q 28.2,6 q 16.3,7 q 36.1,7 p 21.3$, and deletions in 1q42.12, 1q32.2, 1q25.2, 1p33, 2q37.2, 18q22.3, 19p13.2, Xq28, and Xq27.3. GBMs seem to be a heterogeneous group of glial tumors with different clinical course and therapeutic response. Microarray analysis is a useful method to establish a number of possible molecular predictors.
\end{abstract}




\begin{tabular}{|c|c|c|c|}
\hline $\begin{array}{r}\text { Cose Reports in } \\
\text { incisily }\end{array}$ & $\begin{array}{l}\text { Case Rep Oncol 2009;2:103-110 } \\
\text { D0I: } 10.1159 / 000228545\end{array}$ & Published online: July 17, 2009 & $\begin{array}{l}\text { @ } 2009 \text { S. Karger AG, Basel } \\
\text { ISSN 1662-6575 } \\
\text { www.karger.com/cro }\end{array}$ \\
\hline
\end{tabular}

\section{Introduction}

Glioblastoma multiforme (GBM) is the most common glial tumor of the central nervous system. Overall survival is less than a year in most of the cases in spite of multimodal treatment approaches. We describe a case of an adult female patient with histologically confirmed glioblastoma who survived more than 3 years after the initial diagnosis.

\section{Case Report}

A 45-year-old female was admitted at the clinic with short-term history of headache and progressive left-side hemiparesis (mainly of the lower limb). Magnetic resonance imaging (MRI) without contrast enhancement showed right-sided space-occupying lesion involving the precentral white matter adjacent to the midline. Marked compression of the ventricular system, perifocal edema, and imminent subfalcine herniation were also present (fig. 1). Subtotal excision of soft, pinkish-gray-colored, and moderately bleeding tumor lesion was performed by microsurgery. The patient's headache and hemiparesis improved after the intervention. The histological result was glioblastoma with giant cell component (fig. 2). The patient underwent radiotherapy plus concomitant and adjuvant chemotherapy in standard regimens 1 month after the initial surgery, conventional external-beam radiotherapy with a total dose of $60 \mathrm{~Gy}$ and temozolomide. The patient was symptom-free for 35 months following initial surgery with no neuroimaging data of progression of the residual tumor mass (fig. 1). Since July 2008, the patient developed partial motor seizures and progressive hemiparesis in the left side of the body. Local tumor progression was found on the neuroimaging studies (fig. 1). In December 2008 (39 months after the first intervention), second operative procedure was made with subtotal excision of the tumor. No additional neurological deficit developed after the procedure. In April 2009 (44 months after the initial diagnosis), the patient is still alive with moderate neurological deficit. We made microarray analysis of the tumor using genomic array CytoChip and BlueFuse 3.5 software

(http://www.cytochip.com/cytochip) [1]. The following numeric chromosomal aberrations were found: monosomy $8,10,13,22$, and trisomy 21 , as well as amplifications in 4q34.1, 4q28.2, 6q16.3, 7q36.1, $7 \mathrm{p} 21.3$, and deletions in $1 \mathrm{q} 42.12,1 \mathrm{q} 32.2,1 \mathrm{q} 25.2,1 \mathrm{p} 33,2 \mathrm{q} 37.2,18 \mathrm{q} 22.3,19 \mathrm{p} 13.2, \mathrm{Xq} 28$, and Xq27.3 (fig. 3).

\section{Discussion}

Glioblastoma (WHO grade IV glioma) is the most common and most aggressive of all primary brain tumors. Despite multimodal treatment approaches, overall survival is less than a year in most of the cases. However, individual survival varies between patients. Those who survive $\geq 3$ years after the initial diagnosis are defined as long-term survivors (LTSs). The LTSs account for $2-5 \%$ of all cases having GBM [2-7].

According to Shinojima et al. (2004), young age at presentation and female gender are both predictors for long-term survival in cases with GBM. The authors describe 6 cases of GBM patients with a survival of more than 5 years. All 6 were women, with a mean age of 44.2 years [8]. On the contrary, McLendon and Halperin (2003) found a different sex distribution. In a study of 17 LTSs with GBM, 11 were male and 6 female. The average age in the studied group was 40.2 years [6]. No socioeconomic, environmental and occupational factors were associated with the survival in a study on over 55 LTSs with GBM [7].

Scott et al. (1998) studied a population of 279 patients with histologically confirmed GBM. Five (1.8\%) were classified as LTSs (survival range 3.2-15.8 years). Seven LTSs who were initially classified as GBM patients were excluded after neuropathological reevaluation [9]. The need of histological confirmation in LTSs was clearly demonstrated by Kraus and colleagues (2000) [4]. The authors found that 25\% (13/52) of the patients 
initially diagnosed as LTSs were actually mistaken, mostly with anaplastic oligodendroglioma (7), anaplastic oligoastrocytoma (2), anaplastic astrocytoma (3), and anaplastic pilocytic astrocytoma (1) [4]. In 2003, McLendon and Halperin (2003) found that from 32 LTSs initially diagnosed as GBMs, only 17 covered the WHO criteria for grade IV glioma. The authors assumed that intermediate fibrillary elements were more common and small anaplastic elements were less common in LTSs [6]. Shinojima et al. (2004) found giant cell elements on histopathological studies exclusively in long-term survival cases with GBM [8]. Deb and colleagues (2005) investigated 6 long-term survival GBM patients (mean age 9 years, range 5-15). In 3 of them histology was typical, in 2 an oligodendroglial component was present, and in 1 giant cells were identified [10]. The clinical presentation of GBM in LTSs may include headache, nausea and vomiting, seizures, visual disturbances, focal neurological deficits, and cognitive dysfunction. According to some authors, a longer duration of signs and symptoms prior to diagnosis is more likely to be found in LTSs than in short-term survivors (STSs): 52 versus 7.2 weeks [9]. The high Karnofsky Performance Scale (KPS) score at time of diagnosis is a welldefined predictor for prolonged survival in the cases having GBM $[8,9,11,12]$.

MRI is the diagnostic tool of choice for preoperative evaluation of the patients with primary brain tumors. Glioblastomas usually appear as a ring-enhancing lesion with central hypodense core observed on T1-weighted images and a broad surrounding zone of edema apparent on T2-weighted images. At the present time, it is not possible to recognize which patient will become a LTS on the basis of neuroimaging. Mut and coworkers (2007) looked for possible correlations between neuroimaging characteristics and p53 expression in 85 GBM patients. There was no correlation between tumor location, dimension of enhancing lesion, surrounding edema, mass effect, and tumor necrosis and level of p53 expression. A group of GBMs having >50\% p53 expression had ringenhancement pattern and well-defined border on MRI, and they were significantly different from the other p53 subgroups [13].

Treatment approaches in cases with GBM include surgery followed by radio- and chemotherapy. The aim of surgical intervention is to achieve maximal tumor excision with no or with minimal patient deterioration $[3,5,8,14]$. The gross-total tumor removal seems not to be essential for long-term survival in GBM patients. Investigating 22 LTSs with GBM, Chandler and co-workers (1993) found gross-total excision in 2 and subtotal resection in 20 cases [2]. In a study on 17 LTSs, McLendon and Halperin (2003) found gross-total tumor removal in 4 and subtotal resection in 10 cases. Biopsy was performed in one, and unknown tumor resection in 2 cases [6]. Radiotherapy in combination with chemotherapy is defined as the gold standard in the treatment of adult patients with GBM. The standard regimen includes fractionated focal irradiation in daily fractions of 2 Gy given 5 days per week for 6 weeks, for a total of $60 \mathrm{~Gy}$, and continuous daily temozolomide $\left(75 \mathrm{mg}\right.$ per $\mathrm{m}^{2}$ of body-surface area per day, 7 days per week from the first to the last day of radiotherapy), followed by 6 cycles of adjuvant temozolomide (150 to $200 \mathrm{mg}$ per $\mathrm{m}^{2}$ for 5 days during each 28-day cycle) [15]. Most authors agree that a more aggressive multimodal therapeutic approach is associated with prolonged survival $[3,12$, 15]. Interestingly, in 2001, Sabel et al. described a 69-year-old LTS patient with giant cell GBM who had not undergone postoperative radiotherapy or adjuvant chemotherapy. The patient died from unrelated oncologic disease without data for local GBM recurrence [16].

The length of the disease-free period is strongly associated with the patient's overall survival, suggesting that some grade IV gliomas follow a quicker course, with others exhibiting slow growth $[2,9,12,17]$. The need for a second operation in cases with 
recurrent GBM is disputed. According to Pinsker and Lumenta (2001), prolongation of survival time after reoperation was statistically significant only in the subgroup of patients with a KPS score of $\geq 90$ [18]. Filippini et al. (2008) published a study with 676 patients with primary GBM. In $25.0 \%$ of them, reoperation was performed but had no impact on patients' overall survival [12].

Routine histopathological grading has limited capacity to predict survival of patients with GBM [19-21]. Currently, efforts are focused on detecting molecular predictors for GBM survival. Genetic studies show that GBMs consist of several genetic subtypes. The most common genetic alteration is chromosome 10 deletions, especially loss of MMAC/PTEN locus [22]. According to Ushio et al. (2003), PTEN alterations represent a significant unfavorable prognostic factor in the cases having GBM [23]. In 2000, Schiebe and co-workers [24] studied both $\mathrm{mdm} 2$ and 553 gene alterations in 75 GBM patients. They found that $\mathrm{p} 53$ mutation is associated with younger age and prolonged survival, while $\mathrm{mdm} 2$ amplification correlated with worse prognosis. In 2002, Burton and colleagues [25] compared p53 aberrations (expression/mutation), EGFR overexpression, $\mathrm{mdm} 2$ overexpression, and proliferation index in 41 LTSs and 48 STSs. The data suggest that LTSs were more likely to be associated with p53-overexpression, although a statistically significant difference in p53 mutation rate could not be detected. LTSs were less likely to exhibit mdm2 overexpression and showed a lower proliferation rate compared with STSs. Another study of 39 LTSs and 24 STSs found that 19q loss correlates with long-term survival. Multivariate analysis indicated that presentation of 2 or more of the following alterations is associated with short-term survival $(\mathrm{p}<0.01)$ : 6q loss, $10 \mathrm{q}$ loss, and 19q gain [26]. Nigro et al. (2005) studied 34 cases with GBM using microarray CGH and array-based gene expression profiling to identify relationships between gene copy number, gene expression levels, and survival. The loss of chromosome 10 was associated with genome-wide differences in gene expression. The authors found that CHI3L1/YKL40 (1q32.1) was associated with chromosome 10 loss and poorer survival [27]. Epidermal growth factor receptor (EGFR) expression was not detected in any of the long-term survival cases described by Deb and colleagues [10] in 2005. The authors found p53 expression in 4 out of 5 studied patients [10]. In 2005, Korshunov et al. [28] investigated 189 'young adult' patients ( $<50$ years). The survival was shorter in the cases having EGFR amplification and loss of $9 \mathrm{p}$. In contrast, patients having gain of chromosome 9 had more favorable outcome. Later, the same authors described 46 copy number aberrations (CNAs) strongly associated with outcome in GBM patients. Using array-based comparative genomic hybridization (CGH) analysis in 70 GBM cases, they found 26 CNAs associated with STSs, and 20 with LTSs [29]. Houillier et al. (2006) investigated 220 primary GBM patients with the aim of predicting molecular factors. Limited impact was observed only in accordance with MDM2 amplification which was found to be a poor prognostic factor $(\mathrm{p}=0.01)$ [11]. Krex and co-workers (2007) analyzed a group of 55 LTSs. The molecular analyses revealed MGMT hypermethylation in 28 of 36 investigated tumours (74\%). TP53 mutations were found in 9 of 31 cases (29\%) and EGFR amplification in 10 of 38 cases (26\%). Only 2 of 32 cases (6\%) carried a combined $1 p$ and 19q deletion [7]. Hau et al. (2007) confirmed that MGMT promoter methylation is a valuable molecular diagnostic tool to predict GBM response to chemoradiation [30]. In 2008, Marko and co-workers studied 7 GBM patients with more than 24 months and 13 with less than 9 months of survival. The authors used a gene-expression analysis and prospective mathematical classification algorithm to stratify unknown GBMs. They found 43 'fingerprint' genes distinguishing different phenotypes and assumed that unique expression profiles characterize genotypic subsets of GBM associated with patient survival [31]. 


\begin{tabular}{c|l|l|l}
$\begin{array}{c}\text { Cose Reports in } \\
\text { Oncolady }\end{array}$ & $\begin{array}{l}\text { Case Rep Oncol 2009;2:103-110 } \\
\text { D0I: 10.1159/000228545 }\end{array}$ & Published online: July 17, 2009 & $\begin{array}{l}\text { O 2009 S. Karger AG, Basel } \\
\text { ISSN 1662-6575 } \\
\text { www.karger.com/cro }\end{array}$ \\
\hline
\end{tabular}

\section{Conclusion}

GBMs seem to be a heterogenous group of glial tumors with different clinical course and therapeutic response. The microarray analysis is a useful method to establish a number of possible molecular predictors.

\section{Acknowledgment}

This study was supported by Contract No. 18-D/2008 of the Committee of Medical Sciences, Medical University, Sofia, Bulgaria.

Fig. 1. MRI images of the patient before initial surgical procedure in August 2005 (on the left), five months later (middle), and before the second operative intervention in December 2008 (on the right).
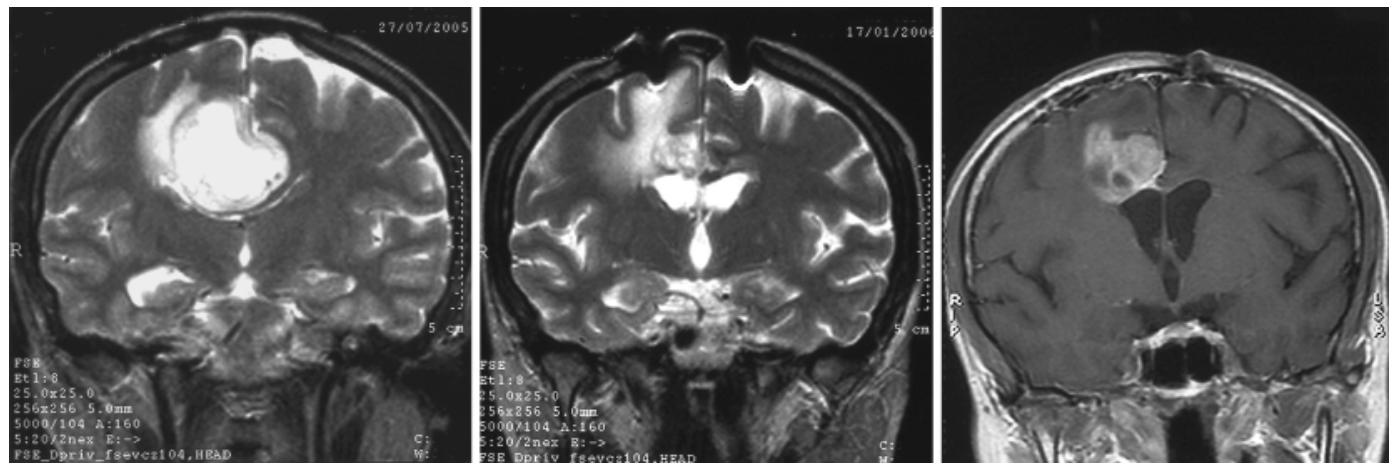

Fig. 2. Routine histological investigation of the tumor after first (on the left, $H \& E \times 250$ ) and second (on the right, $H \& E \times 100$ ) operative interventions. Significant number of bizarre, multinucleated giant cells as well as marked cellularity, hyperchromatism, pleomorphism, prominent neovascularization, and areas of pseudopalisading necrosis were present on both tumor samples.
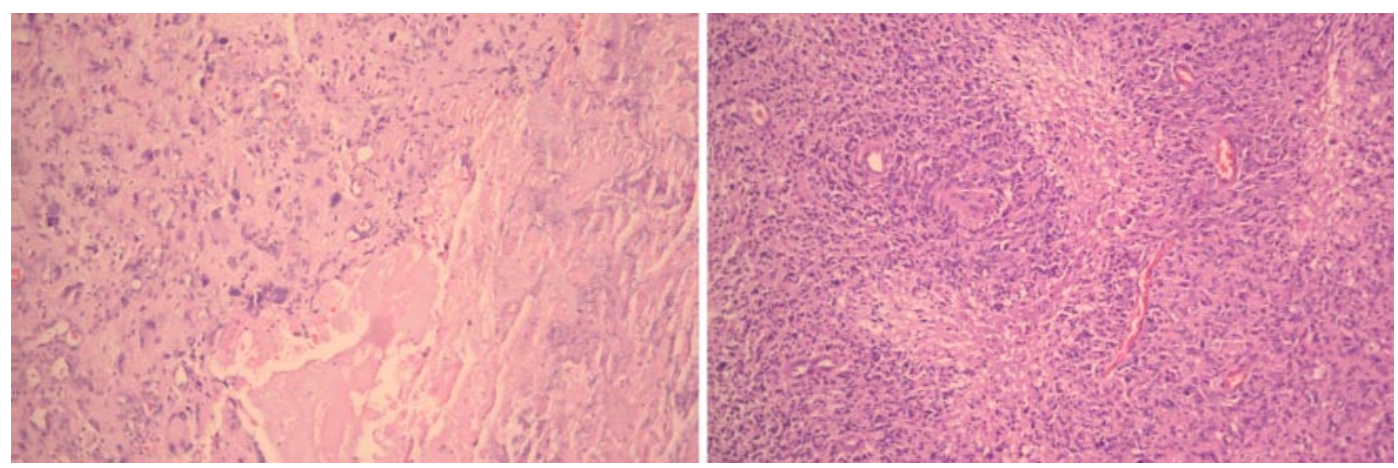


\begin{tabular}{c|l|l|l}
$\begin{array}{c}\text { Cose Reports in } \\
\text { Oncolay }\end{array}$ & $\begin{array}{l}\text { Case Rep Oncol 2009;2:103-110 } \\
\text { D0I: } 10.1159 / 000228545\end{array}$ & Published online: July 17, 2009 & $\begin{array}{l}\text { O 2009 S. Karger AG, Basel } \\
\text { ISSN 1662-6575 } \\
\text { www.karger.com/cro }\end{array}$ \\
\hline
\end{tabular}

Fig. 3. The microarray analysis of the tumor obtained during the second operative intervention demonstrated monosomy $8,10,13,22$, and trisomy 21 , as well as amplifications in $4 \mathrm{q} 34.1,4 \mathrm{q} 28.2$, $6 \mathrm{q} 16.3,7 \mathrm{q} 36.1,7 \mathrm{p} 21.3$, and deletions in $1 \mathrm{q} 42.12,1 \mathrm{q} 32.2,1 \mathrm{q} 25.2,1 \mathrm{p} 33,2 \mathrm{q} 37.2,18 \mathrm{q} 22.3,19 \mathrm{p} 13.2$, Xq28, and $\mathrm{Xq} 27.3$.

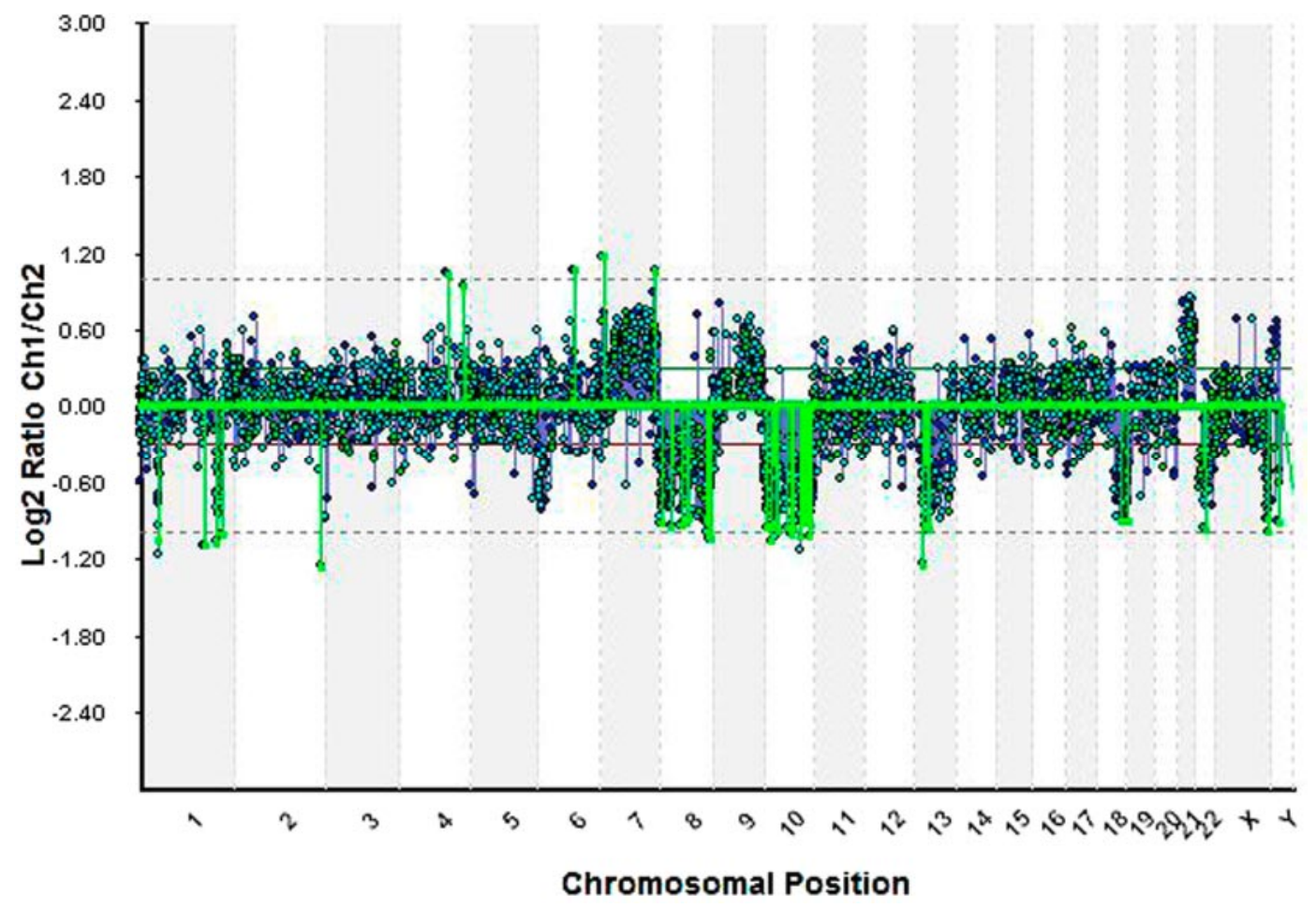




\section{References}

1 http://www.cytochip.com/cytochip.

-2 Chandler KL, Prados MD, Malec M, Wilson CB: Long-term survival in patients with glioblastoma multiforme. Neurosurgery 1993;32:716-720.

-3 Scott JN, Rewcastle NB, Brasher PM, Fulton D, MacKinnon JA, Hamilton M, Cairncross J, Forsyth P: Which glioblastoma multiforme patient will become a long-term survivor? A population-based study. Ann Neurol 1999;46:183-188.

4 Kraus JA, Wenghoefer M, Schmidt MC, von Deimling A, Berweiler U, Roggendorf W, Diete S, Dietzmann K, Müller B, Heuser K, Reifenberger G, Schlegel U: Long-term survival of glioblastoma multiforme: importance of histopathological reevaluation. J Neurol 2000;247:455-460.

5 Chamberlain MC: Treatment options for glioblastoma. Neurosurg Focus 2006;20:E2.

6 McLendon RE, Halperin EC: Is the long-term survival of patients with intracranial glioblastoma multiforme overstated? Cancer 2003;98:1745-1748.

7 Krex D, Klink B, Hartmann C, von Deimling, Simon M, Sabel M, Steinbach JP, Heese O, Reifenberger G, Weller M, Schackert G: Long-term survival with glioblastoma multiforme. Brain 2007;130(Pt 10):2596-2606.

8 Shinojima N, Kochi M, Hamada J, Nakamura H, Yano S, Makino K, Tsuiki H, Tada K, Kuratsu J, Ishimaru Y, Ushio Y: The influence of sex and the presence of giant cells on postoperative long-term survival in adult patients with supratentorial glioblastoma multiforme. J Neurosurg 2004;101:219-226.

9 Scott JN, Rewcastle NB, Brasher PM, Fulton D, Hagen NA, MacKinnon JA, Sutherland G, Cairncross JG, Forsyth P: Long-term glioblastoma multiforme survivors: a population-based study. Can J Neurol Sci 1998;25:197-201.

10 Deb P, Sharma MC, Mahapatra AK, Agarwal D, Sarkar C: Glioblastoma multiforme with long term survival. Neurol India 2005;53:329-332.

11 Houillier C, Lejeune J, Benouaich-Amiel A, Laigle-Donadey F, Criniere E, Mokhtari K, Thillet J, Delattre JY, Hoang-Xuan K, Sanson M: Prognostic impact of molecular markers in a series of 220 primary glioblastomas. Cancer 2006;106:2218-2223.

12 Filippini G, Falcone C, Boiardi A, Broggi G, Bruzzone MG, Caldiroli D, Farina R, Farinotti M, Fariselli L, Finocchiaro G, Giombini S, Pollo B, Savoiardo M, Solero CL, Valsecchi MG: Prognostic factors for survival in 676 consecutive patients with newly diagnosed primary glioblastoma. Neuro Oncol 2008;10:79-87.

13 Mut M, Turba UC, Botella AC, Baskurt E, Lopes MBS, Shaffrey ME: Neuroimaging characteristics in subgroup of GBMs with p53 overexpression. J Neuroimaging 2007;17:168-174.

14 Pichlmeier U, Bink B, Schackert G, Stummer W; the ALA Glioma Study Group: Resection and survival in glioblastoma multiforme: an RTOG recursive partitioning analysis of ALA study patients. Neuro Oncol 2008;10:1025-1034.

15 Stupp R, Mason WP, van den Bent MJ, Weller M, Fisher B, Taphoorn MJ, Belanger K, Brandes AA, Marosi C, Bogdahn U, Curschmann J, Janzer RC, Ludwin SK, Gorlia T, Allgeier A, Lacombe D, Cairncross JG, Eisenhauer E, Mirimanoff RO: Radiotherapy plus concomitant and adjuvant temozolomide for glioblastoma. N Engl J Med 2005;352:987-996.

16 Sabel M, Reifenberger J, Weber RG, Reifenberger G, Schmitt HP: Long-term survival of a patient with giant cell glioblastoma. Case report. J Neurosurg 2001;94:605-611.

17 Mineo JF, Quintin-Roue I, Lucas B, Buburusan V, Besson G: Glioblastomas: clinical study and search for prognostic factors. Neurochirurgie 2002;48:500-509.

18 Pinsker M, Lumenta C: Experiences with reoperation on recurrent glioblastoma multiforme. Zentralbl Neurochir 2001;62:43-47.

19 Senger D, Cairncross JG, Forsyth PA: Long-term survivors of glioblastoma: statistical aberration or important unrecognized molecular subtype? Cancer J 2003;9:214-221.

20 Benjamin R, Capparella J, Brown A: Classification of glioblastoma in adults by molecular genetics. Cancer J 2003;9:82-90.

21 Wrensch M, Fisher JL, Schwartzbaum JA, Bondy M, Berger M, Aldape KD: The molecular epidemiology of gliomas in adults. Neurosurg Focus 2005;19:E5. 
22 Steck PA, Lin H, Langford LA, Jasser SA, Koul D, Yung WK, Pershouse MA: Functional and molecular analyses of 10q deletions in human gliomas. Genes Chromosomes Cancer 1999;24:135-143.

23 Ushio Y, Tada K, Shiraishi S, Kamityo T, Shinojima N, Kochi M, Saya H: Correlation of molecular genetic analysis of p53, MDM2, p16, PTEN and EGFR and survival of patients with anaplastic astrocytoma and glioblastoma. Front Biosci 2003;8:281-288.

24 Schiebe M, Ohneseit P, Hoffmann W, Meyermann R, Rodemann HP, Bamberg $\mathrm{M}$ : Analysis of mdm2 and p53 gene alterations in glioblastomas and its correlation with clinical factors. J Neurooncol 2000;49:197-203.

25 Burton EC, Lamborn KR, Forsyth P, Scott J, O’Campo J, Uyehara-Lock J, Prados M, Berger M, Passe S, Uhm J, O’Neill BP, Jenkins RB, Aldape KD: Aberrant p53, $\mathrm{mdm} 2$, and proliferation differ in glioblastomas from long-term compared with typical survivors. Clin Cancer Res 2002;8:180-187.

26 Burton EC, Lamborn KR, Feuerstein BG, Prados M, Scott J, Forsyth P, Passe S, Jenkins RB, Aldape KD: Genetic aberrations defined by comparative genomic hybridization distinguish long-term from typical survivors of glioblastoma. Cancer Res 2002;62:6205-6210.

27 Nigro JM, Misara A, Zhang L, Smirnov I, Colman H, Griffin C, Ozburn N, Chen M, Pan E, Koul D, Yung WK, Feuerstein BG, Aldape KD: Integrated arraycomparative genomic hybridization and expression array profiles identify clinically relevant molecular subtypes of glioblastoma. Cancer Res 2005;65:16781686.

28 Korshunov A, Sycheva R, Golanov A: The prognostic relevance of molecular alterations in glioblastomas for patients age $<50$ years. Cancer 2005;104:825-832.

29 Korshunov A, Sycheva R, Golanov A: Genetically distinct and clinically relevant subtypes of glioblastoma defined by array-based comparative genomic hybridization (array-CGH). Acta Neuropathol 2006;111:465-474.

30 Hau P, Stupp R, Hegi ME: MGMT methylation status: the advent of stratified therapy in glioblastoma? Dis Markers 2007;23:97-104.

31 Marko NF, Toms SA, Barnet GH, Weil R: Genomic expression patterns distinguish long-term from short-term glioblastoma survivors: a preliminary feasibility study. Genomics 2008;91:395-406. 